\title{
Harmonization of improvement of legal and technical regulation of underground space development in Russian cities
}

\author{
Valery Belyaev ${ }^{1, *}$ \\ ${ }^{1}$ Moscow University of Civil Engineering, Yaroslavskoe shosse, 26, Moscow, 129337, Russia
}

\begin{abstract}
The features of legal and technical regulation are considered and the main shortcomings of these systems of public administration are identified. It is shown that they hinder the effective development of the underground space of Russian cities as a promising area of urban development. A related analysis of the results of the author's monitoring of regulatory documents in the field of integrated urban development of underground space, as well as the interim results of the legal research initiated by him, aimed at eliminating defects in federal legislation, is presented. In the context of legal regulation and trends in its development, a new Set of Rules (SR 473) concerning «underground urban planning»is analyzed in detail. The conclusion is made about the systemic shortcomings of this document, which are based on the subjective factor of the manifested «legal nihilism» in combination with the objective deficit and imperfection of the legislative sphere. Proposals are given for the harmonization of amendments and additions to SR 473 and other documents on standardization, depending on the nature and timing of the adoption of legislative initiatives. The topics discussed are of interest not only because of their novelty, but also because of the reality and prospects of the proposed administrative steps that can give impetus to spatial development on the model of a sustainable, viable and compact city.
\end{abstract}

\section{Introduction}

Thee implementation of the model of a sustainable, viable and compact city, which is now generally recognized [1], involves, among other things, the provision of intensive and integrated urban development of urban underground space (hereinafter also referred to as UUS). Moreover, the effectiveness of this method of urban planning has already been proven by the best practices of a number of developed countries.

The underground vector of development of its territory is relevant for Moscow and other major Russian cities, especially since they have accumulated a reserve in this part even during the planned economy. However, in recent decades, there has been a noticeable decline in the scale, intensity and complexity of the development of UUS with the continuation of the practice of «loosening» urban areas. A striking example is the purely administrative decision to annex huge adjacent territories to the city of Moscow in 2012,

* Corresponding author: vbelyaev2011@mail.ru 
which significantly reduced the motivation for the development of the underground part of the capital's territory. Leaving aside the historical and mental roots of extensive urban land use in Russia, note that this negative trend is largely connected with the imperfection of the system of public administration, and especially with defects subsystems regulatory and normative-technical regulation (standardization) in the field.

With regard to the development of UUS, the article reflects the main provisions and some results of the following analytical developments:

1. Scientific research on the monitoring and analysis of regulatory documents in the field of integrated urban development of UUS (with an emphasis on standardization) in this area. The study was conducted under the supervision of the author of this article in 20172019 [2].

2. Research and development of new legislation on the integrated development of the UUS of the largest cities, which provides for a number of innovations in the field of public administration of urban development, fundamental changes in the state regulation of planning, creation and use of UUS (hereinafter also referred to as «Legal Research»), https://moscow.tendermedia.ru/lot/show/33544314. The work is carried out on the initiative and with the participation of the author as an expert and consultant, starting in 2020, and is currently in the final stage. The result should be the adoption of legislative and other regulatory legal acts that comprehensively regulate the issues of urban development of UUS.

The article also reflects the practice of the author's expert and organizational activities as a member of the Subcommittee 9 «Urban Planning» of the Technical Committee 465 «Construction» of the Federal Agency for Technical Regulation and Metrology (hereinafter - the Subcommittee 9) and in the section «Urban Planning and Underground Urbanism» of the Joint Scientific and Technical Council for Urban Planning Policy and Construction of the City of Moscow (the author is the scientific secretary of the Subcommittee 9 and the section).

\section{Materials and methods}

The need for research was caused by the growing relevance of underground urbanism, the complexity and lack of knowledge of the tasks, the fragmentary nature of approaches to the development of UUS and to its regulation (standardization). In terms of monitoring legal regulation, the authors followed the methodology established by national regulatory requirements (legal research and analysis of the results of normative activity, as well as the quality of regulatory legal acts, and the effectiveness of their implementation). The main functions and types of work in this case consisted in identifying the array of subject legal acts, analyzing their completeness (redundancy) and consistency.

In relation to the monitoring of regulatory technical documents (hereinafter also referred to as RTD), there are no such uniform requirements. In this regard, the general logic of the «technological» scheme of the study was adopted by analogy. First, the collected information was monitored and analyzed in terms of assessing the effectiveness of the RTD (unity of terminology, completeness, consistency and sufficiency of parameterization of requirements, compliance with legislation, orientation to modern innovative technologies and best world practices). Then, taking into account this assessment, the identification and analysis of negative aspects in the field of standardization of engineering surveys, planning and design of urban development of UUS was carried out. With particular detail, the author analyzes the composition of SR 473, taking into account that this document on standardization in relation to the field of UUS development is new and special (subject). Based on the results of the monitoring, recommendations for improving regulation are given. 


\section{Results and discussion}

The development of UUS by creating (construction) underground buildings and structures (hereinafter referred to as UBS), that is is part of urban relations [3]. At the same time, urban planning legislation does not specify the specifics of the development of UUS. Based on the mandatory nature of this legislation, this fact should be considered as a legal gap, which, however, has the possibility of compensation by the norms of other («related») legislation [3]. However, this does not happen, moreover, the legislation on mineral resources, for example, has a clear mining context with the ideology of not developing, but protecting the subsoil for the purposes of mining. At the same time, the entire cumbersome administrative procedure (the model of preliminary approval of the construction object, licensing, etc.) is mechanically transferred to the case of «construction subsurface use». As a result, there are contradictions with modern and more «market» urban planning legislation (leveling the model of urban planning design, performing engineering surveys, construction expertise, etc.).

At the initiative of the author of this article, the issue was considered within the walls of the State Duma and the Government of the Russian Federation. As a result, at the request of the authorized department of the Moscow Government, with the participation of the author, research work is being carried out to prepare amendments and additions to the legislation (on urban planning, land, civil, on subsoil, on state cadastral registration and real estate registration) aimed at removing obstacles to the development of the UUS. Moreover, in formulating the goal, objectives, and subject of the study, the customer and developers tried to strategically proceed from a broader, systematic view of the problem. Below, in the context of a comparative analysis of the problems of legal and technical regulation (standardization), some significant provisions of the research are considered.

As you know, the standardization block is the most important component of the effective functioning of the public administration system in market conditions. It is primarily aimed at ensuring the safety and quality of products or their production processes. However, in relation to the products of urban planning activities, this block has a number of features: the uniqueness of the «territory» itself, the complexity of capital construction projects (hereinafter also referred to as CCP) as products of such activities, their piecemeal nature and an increased level of responsibility (risk). The processes of creation and economic use of CCP are also specific, such as engineering surveys, design, construction, operation and demolition of CCP. The scale of the above-mentioned specifics increases when creating a UBS. Many UBSs and their complexes belong to the category of particularly dangerous, technically complex and unique objects with an increased service life and more stringent design requirements $[3,4]$.

If we consider the planning («urban planning») level, then the system of rationing for it is even more specific, since the object of «rationing» is no longer a separate object, but a model of the development of the urban territory itself. In our opinion, social and other urban contexts (ecological, cultural, historical, etc.) should also be taken into account.

A retrospective review showed that the formation of the Russian underground urbanism dates back to the period of the $70 \mathrm{~s}$ of the last century. Under the planned economy, rationing in the urban planning system was carried out by approving building codes and regulations (SNiP). They were adopted by the state branch executive authority and were mandatory for application. In addition, the regions adopted territorial building codes (TSN). At the central (union, republican) and regional levels, methodological documents were approved, which also played an important role in the rationing of construction.

For example, the executive authority of the city of Moscow in 1978 approved Recommendations for the use of underground space in Moscow. They were based on the decisions of the approved General Plan of the city and the Scheme of organization and use 
of the underground space of the city of Moscow, approved in 1975. These documents and Recommendations were not subject to publication at the time. The recommendations were of a systematic nature, primarily due to the fact that their preparation was based on the results of special scientific research and on the results of experimental design. Later, the provisions of the Recommendations were included in some Moscow City Building Regulations (MGSN), which also had the status of mandatory application.

Based on the Moscow Recommendations, a similar document (Guide) was prepared for other cities in the country [5]. It detailed certain substantive provisions of the normative document on urban planning (SNiP II-60-75) in order to «at least partially fill in the lack of normative and methodological documents in the field of integrated use of GPP». Later, this Manual was reworked into another methodical document - «Guidelines for the integrated development of the underground space of large cities» [6] and was taken as the basis for a modern document-SR 473, discussed below [7].

During the years of political and economic transformation, the lack of standardization in terms of urban development of UUS has even increased, as during the reform of the technical regulation system, the regions lost the opportunity to adopt their TSP [3]. In particular, in fact, the MGSN was also abolished. However, there is no adequate replacement of regional TSN with new federal documents, which is confirmed in the course of our monitoring of the main national standards and codes of rules (SR) of both mandatory and voluntary application. The focus of the monitoring was on the complexity (integrality) of the UUS development, as well as on the block of documents in the section «Urban Planning», as having the greatest managerial (regulatory) potential.

Paradoxically, it is this planning level of standardization, which also has the abovementioned features, that the Ministry of Construction of the Russian Federation (hereinafter also referred to as the Ministry of Construction) does not pay due attention to. In this regard, Subcommittee 9 sent its proposals to the leadership of this Ministry in 2020. It is proposed, in particular, to supplement the JV line with a number of state standards, which will increase the range of regulation and the degree of compliance with the best world standards. A radical organizational step is, in our opinion, the formation of a new Technical Committee «Urban Planning».

The RTD monitoring was carried out by us in 2017 as part of the research work commissioned by the Federal Center for Standardization as a special unit of the Ministry of Construction [2]. He showed that there is no single document on the implementation of standardization of the integrated development of UUS, and the existing RTDs mainly contain requirements for the creation of separate CCPs without taking into account the options for their joint placement and the possibility of using other UUS services (see below). Gaps and conflicts in the composition of the RTD require the cost of developing special technical conditions for the preparation of project documentation. In general, the national regulatory and technical framework for the development of UUS is conceptually significantly outdated, not meeting modern needs.

In this regard, we have justified and proposed a targeted and systematic development of this base by developing a basic RTD that regulates the integrated urban development of UUS, as well as by preparing a set of interrelated special RTD and additional sections of existing RTD. The structure of the basic document - SR «Integrated urban development of underground space. Basic provisions», as well as a list of relevant research topics that should provide justification for the composition and content of specific requirements of the new standards.

Unfortunately, the proposals were not reflected in the plans of the Ministry of Construction. Moreover, without the necessary scientific justification and without the mandatory approval of the Subcommittee 9, the 2019 plan included the development of a project for a different SR with the original name «Urban planning. Planning and 
construction of underground space». The document was approved by the Ministry of Construction as SR 473.1325800.2019 «Underground buildings, structures and complexes. Rules of urban planning design» (SR 473) and entered into force in the summer of 2020 [7].

Next, we will consider in more detail the main provisions of SR 473 in the context of a comparative analysis of the sufficiency of the legal regulations necessary for the implementation of the requirements of SR 473. First of all, we note that the name of SR 473 generally corresponds to one of the compromise options proposed by us. In particular, it is recorded that buildings are also included in the composition of underground objects, which corresponds to the legislation $[3,4]$. At the same time, the term «urban planning» is illegitimate, since it is not included in [3]. This already sets the name conflict with the structure (composition) and scope of SR 473 (we proposed an option - «Rules for placement and design»). Namely, the composition of SR 473 is much broader, it also includes requirements for design, construction, reconstruction, operation, conservation and demolition, which do not relate to «urban planning design», but to the subsequent stage of implementation of documents (documentation) of «urban planning design». We believe that these requirements should be excluded from the composition of SR 473, especially since they largely duplicate the existing documents on standardization. Moreover, it is logical to limit the range of requirements to the level of the largest and largest city (urban district) for which the issues under consideration are most relevant, without considering the levels of the region and the municipal district. The latter also looks tactically correct, allowing to reduce the severity of interdepartmental disagreements with the Federal Ministry of Economic Development, which is responsible for territorial planning issues (the presence of disagreements indirectly illustrates the fact that there is no coordination of the draft SR 473 with the specified Ministry, which is mandatory).

Questions of legitimacy and unity of terminology are extremely important. The analysis showed that both the legislation and the RTD system do not meet the principle of sufficiency and consistency of basic terms and definitions in relation to the development of UUS, which in practice leads to uncertainty in the legal regulation of relations. At the same time, it is known that any standardization document should establish not legal, but technical standards, which at the same time cannot contradict the legislation (the principle of subordination) $[4,8]$. This principle is not observed in our case, firstly, because a number of terms and definitions of SR 473 do not fully correspond to the Urban Planning, Land and Civil Codes and other federal laws. The very definition of the term «underground space» does not take into account that, according to the Law on Subsoil, it is an integral part of the «subsoil» [9] and may also include «soil». Meanwhile, for example, in Moscow, the layer of the soil layer, due to regional legislation, is $1 \mathrm{~m}$ and it contains, among other things, a number of linear objects of municipal infrastructure. It is also necessary to take into account that, according to the law, not «underground space» can be used, but an individually defined immovable thing - a subsurface area or a UBS $[9,10]$. Finally, in the scope of the definition of «underground space» and hereinafter SR 473 is not taken into account that in the world of urban planning practice, in particular on the model of «Deep city» UUS is also a resource and other services (geo-energy, geo-materials, underground water etc.) [11], and the term «underground» is used in the singular.

We believe that the basic term «underground space» in the physical sense, it is advisable to understand the underground part of the territory (e.g., countries, cities, land), i.e. the three-dimensional space, located below the grade level of the available land for use in urban purposes (a UBS, the use of resources geo-energy, geo-materials, groundwater and other services), which includes soil and the upper part (layer) of the earth. In legal terms, the depth limit of the UUS can be set by law. The authors of the» Legal Study» propose to fix the limit of the legal regime of the land plot on the experience of Singapore at the level of $30 \mathrm{~m}$, which in our opinion requires additional justification. Despite the fact that at first 
in SR 473 the definition of the UUS is given close to the above, then the UUS is considered not as «space», but as «underground structures» (section 6). From the standpoint of logic, such substitution of the content of the basic term is certainly unacceptable.

As already noted, some of the terms used in SR 473 are not fixed in [3], so they cannot be considered legitimate («urban planning documentation», etc.). Also, in our opinion, the definitions of such basic terms as «object of underground space», «use of underground space», "planning structure of underground space», "complex development of underground space», «reuse of underground space», etc. need additional disclosure. c ensuring their uniformity. Based on the legal requirements $[3,4,10]$, it would be necessary to give the concepts and other terms: «underground building», "part of an underground building», «buried building», «buried structure» with the formulation of the corresponding requirements for them. At the same time, it is necessary to ontologically harmonize the use of terms in the text, to exclude some conflicts, violations of the generally accepted rules of division of concepts and other requirements of formal logic. For example, it is often indicated that the signs themselves need additional regulatory consolidation.

In the «Legal Research», considerable attention is paid to the issues of terminology, although not all the necessary terms have found their definition in it. In particular, the terms related to the creation of metro facilities are not disclosed (in general, the refusal to consider the legal issues of creating such facilities is certainly erroneous, since they usually represent the framework for the development of UUS). In addition, it is advisable to provide additional clarification of the proposed scheme of types of concepts and their characteristics in the context of central, basic, special terms, and also try to draw a parallel with world practice. Despite these shortcomings, in accordance with the above-mentioned principle of subordination, the terminology in SR 473 should be revised and supplemented accordingly in connection with the results of the legal studies conducted.

It should be recognized that in this case, following the principle of subordination is not only key, but also problematic. This is due to the lack of legal regulation of the development of UUS and other systemic defects in this area, indicated above. If we follow the formal requirements, then a number of key provisions that are of a legal nature, as well as those that contradict the legislation or are not regulated by it, should be excluded from the composition of SR 473 or substantially revised. Among them, first of all, there will be requirements for territorial planning (preparation of a special section of the "city master plan» or a scheme for the organization and use of UUS) and territory planning. Such requirements by their nature relate to the legal regulation, the features of which for the case of underground urban planning are also not yet established [3]. In the course of the «Legal Research», the main proposals for the level of planning of the territory have been developed, but the provisions on «general» planning require additional research (the focus is shifted towards strategic planning in combination with urban zoning). After the addition and during the legislative implementation of these legal proposals, the relevant requirements of SR 473 should be finalized in conjunction with them. In general, as a result, only those technical requirements that directly relate to the development of UUS should be included in the composition of SR 473.

It is necessary to exclude direct duplication of other documents on standardization, which is not allowed [8]. Thus, the requirement for the need for integrated use of UUS in the largest cities « is borrowed from another SR [12]. However, even when assigned to a group of mandatory requirements, this requirement does not «work» in practice for the same reason - it has a legal format, and it is not yet fixed in the legal field. Other references to [12], however, are also meaningless also because of the absence in [12] of modern reasonable parameters for rationing the development of UUS.

In the section «Typology and general organization of the underground space», only separate declarations are given in relation to the UBS, and the actual typology of the UUS 
is not disclosed. Meanwhile, it was on this basis that it was advisable to distinguish and make the appropriate requirements. The revision of SR 473 in this case should also take into account the proposals of the «Legal Research» (differentiation of the UUS at different levels of depth, etc.). In particular, you should clarify the nature and method of the proposed «zoning», its role and place subject to the laws ([3], http://www.consultant.ru/document/cons_doc_LAW_289833/) and the properties of «crossborder» of underground infrastructure and other UBS (they are in the depth more than $5 \mathrm{~m}$ can freely cross the boundaries of any of the functional areas established by the General plan of the city). This issue is not yet sufficiently reflected in the «Legal Research» and also requires additional research.

A number of other provisions of SR 473 also require justification and clarification, including those on the special «planning structure of the UUS» and on the boundaries of territorial zones, which, according to [3], are established by urban planning («legal») zoning. The specifics of such zoning for the development of UUS in SR 473 are omitted, although it is effectively used in the world [13]. To eliminate this omission, it is necessary to take into account the radical proposals of the «Legal Research» in this regard. In a number of cases, it is proposed to establish (as part of the Rules of Land Use and Development) a legal regime for the use of not only land plots and CCP, but also subsurface areas of local significance. It is also necessary to take into account the proposals regarding the legal regulation of the preparation of standards for urban planning design (the requirements for them are not given in SR 473).

Some other proposals of SR 473 also need to be clarified, in particular on the «adaptation» of cultural heritage objects using UUS and on the establishment of a single UUS during the «renovation of districts». They are not yet provided for by the legislation, nor by the «Legal Research», nor by the documents on standardization. At the same time, given the importance of this area for Moscow, the work plan for 2021 of the section «Urban planning and underground Urbanism» includes the issue of conducting experimental design in one of the areas of renovation of the capital's housing stock.

Note the excessively cautious approach of the authors of SR 473 to the development of UUS industrial zones, which is proposed to be allowed only with «appropriate justification». We consider it erroneous, since industrial land in Russia is clearly used extensively, including due to the minimum level of development of UUS. Most of the provisions and parameters of both this and other sections of SR 473 (on the functional distribution of UUS by depth levels, on the types of use of UBS, on the limitations of the use of UUS, etc.) require their justification and confirmation by practice (validation, approbation). Some suggestions in this regard are given in the «Legal Research». When taking them into account, it is also necessary to remember that the requirements of any SR must meet the best international and domestic standards [8].

In the section «Basic requirements for the formation of underground space», the disclosure of both the essence of such formation and its detailing at different levels of» urban planning design « is not fulfilled. Instead of well-founded technical requirements are given General guidelines (for design use UUS to promising schemes «development areas» and «development of the underground», on the formation of ensembles and complexes «are linked by a system of underground spaces», to create a multifunctional UUS, the program of development of UUS as part of the project «the line or the network of the metro», UUS «historic areas», etc.). The opportunity to implement them as yet nothing of the normative is not confirmed and is poorly represented in the «Legal research.» As for the references to other SRS, they are not accompanied by the required substantive proposals for harmonization with such SRS as primary sources. Moreover, some of them, such as SR 395 on the design of transport interchange hubs (TIHs), do not even contain relevant requirements for the development of UUS. It is also incorrect that if there are such 
requirements in other SRs, they are transferred to SR 473 without reference to the original source.

The title of the section «Design of underground space in urban planning documentation» implies the disclosure of the features and specific requirements for the development of UUS as part of territorial planning, urban zoning and territory planning, including materials for justification. Instead, there is fragmentation, the inclusion of individual and poorly justified requirements in other sections outside of a clear link to the types of «urban planning documentation». This indicates the need to optimize the structure of SR 473 (we made proposals in this regard within the framework of Subcommittee 9, but also ignored them). Along with the duplication of several noted above illegitimate demands in terms of planning UUS proposed General plan of the big city to Supplement the section «Integrated development UUS» with the «General scheme of the organization and use UUS», sections and diagrams for its development. However, this is not provided for by the legislation and is not seen in the prospects for its improvement (the «Legal Research» at this level is limited to a general consideration of the task of differentiating the UUS by purpose, including the depth of urban development, and in it the key aspect of complexity, unfortunately, is not yet sufficiently developed).

The requirements for determining the «dimensions» of the UBS when planning the territory do not correspond to the legislation, as it does not yet provide for the norms for «mutually agreed placement of objects of ground and underground construction» [3] . In addition, the issues of red lines are not relevant for the creation of a UBS (see above about the cross-border nature of the placement of a UBS).

From SR 473, it is necessary to exclude provisions that do not relate to the subject of «urban planning design» (assessment of economic feasibility, disposal of real estate) or adjust them in the necessary context. At the same time, SR 473 should be supplemented with provisions on the preparation of a draft planning land division. These issues are significant for the design of UBSs created by the open construction method and in the «Legal Research» they are given considerable attention.

A number of legislative urban planning and land innovations of federal laws $[3,14]$ and by-laws have significantly streamlined the establishment of borders and legal regimes of zones with special conditions for the use of the territory (corresponding restrictions on the territory of such zones). It is important that the volume of such restrictions is significantly less underground than on its surface, which is a planning bonus for the development of the UUS (the degree of «planning freedom» increases). In SR 473, the proposals in this part (for example, for technical zones) are incomplete and not quite correct. They should be supplemented and brought into line with legal norms, and set out in the format of «technical» requirements on the nature and scope of the relevant restrictions (note that the issue requires additional research).

When standardizing, it is advisable to focus on infrastructure objects, primarily on linear UBS and complexes (it is necessary to formulate requirements for the placement and urban planning design of metro stills, TIHs, communication city collectors, and their integration with other CCPs). It is important to understand how the innovative «underground construction technologies» outlined in SR 473 will be applied. At the same time, the system of legal support in terms of the integrality of the development of the UUS, as already noted, should be finalized.

In the section «Special requirements for performing engineering surveys», in the context of the above-proposed clarification of the UBS typology, it is necessary to emphasize the features of performing engineering surveys (hereinafter - ES) for the purposes of mastering the UUS. At the same time, there are special requirements for performing not only engineering-geological, but also other types of AI. This should be further delineated situation through the levels of the design (including the stage of establishment functional 
areas), the terms of the placement of UBS and their complexes, the type-site (built or unbuilt) the UBS and how they are created (open or closed). With the proposed change in legislation, it will also be necessary to carry out surveys in order to describe new or modified boundaries of three-dimensional underground volumes (subsurface areas). Therefore, for the case of construction without opening the earth's surface, it is advisable to indicate the provision of a link with the measurements that are usually carried out during mining operations in the subsurface.

It is also important to note a number of significant points in this section of SR 473, namely:

- clarify the criteria for the sufficiency and reliability of the source data for ES, specify the requirements for the case of their absence and the requirement for «minimum volumes» of ES;

- describe the method for determining the category of complexity of engineering and geological conditions (zoning or other method), based on the requirements of SR 47 as the basic document for the implementation of all ES (https://minstroyrf.gov.ru/docs/13629/);

- clarify the proposals for classifying geological and engineering-geological conditions as legal restrictions, for tracing options for the placement of UBS, performing ES during operation, monitoring, control drilling for their compliance [2], [15], SR 47, SR 438 (https://minstroyrf.gov.ru/docs/18473/), SR 446 (https://minstroyrf.gov.ru/docs/18797/) and other regulatory documents;

- note that engineering and geological zoning as a result of ES is carried out with the preparation of assessment maps, as well as maps (schemes) of the distribution and risk assessment of hazardous processes and phenomena;

- provide that in the conditions of the surrounding development, the results of the ES should contain data on the stress-strain state of the soil layer;

- emphasize the orientation of the ES results to the 3D format of the engineering digital terrain model with full inclusion in the model of the geological environment (information modeling issues should be reflected in other sections of SR 473).

- indicate the information interaction with the state funds of spatial data and information on subsurface exploration (for the case not related to the extraction of minerals);

- exclude meaningless references to special SRS that do not contain requirements for the implementation of ES for the development of UUS (this also applies to other sections of SR 473).

The sections «Special requirements for architectural and construction design» «Requirements for the choice of technologies for complex development of underground space» and «Basic requirements for the construction, operation and liquidation of underground facilities and structures» as indicated above do not correspond to the name and scope of SR 473, are mainly of a reference nature. Comments and suggestions on them are available, but in this regard are not provided in this article.

In general, the provisions of all sections and annexes of SR 473 require additional mutual coordination, elimination of internal duplication and editorial revision.

\section{Conclusions}

From it follows that the main problem of the legal and technical regulation of underground space development of Russian cities is not only to delay the process of improving these vital systems of government, but in the discord, in the absence of the required departmental and other coordination, strategic and conceptual installations, the weakness of the scientific study. As a result, in particular, there is a gap in attempts to develop regulatory and technical regulation in the field of UUS development and in the development of the legal framework. As a result, for example, many of the key requirements of SR 473, as well as 
some other subject documents on standardization, are deprived of support in the form of fixed legal norms and cannot be applied.

The solution of the problem has the prospect of resolution in the implementation of the results of scientific research of a legal nature initiated by the author of the article. Most likely, the path to such implementation will not be quick and easy, on the one hand, due to the radical nature of a number of proposals (primarily concerning the introduction of a conservative sphere of regulation of subsurface use), on the other-due to the need for additional justification of the above and other proposals of the «Legal Research».

At the same time, it is obvious that with the addition of legal justifications and with the expected support from the Government of the Russian Federation and the Government of Moscow, the developed draft law will be submitted to the State Duma for consideration. In parallel, we consider it appropriate:

1. The Ministry of Construction should ensure the implementation of the relevant scientific justifications for the purpose of making amendments and additions to SR 473 and other documents on standardization in the context of the adjustment of federal legislation.

2. The Government of Moscow should clarify and supplement the draft regional normative legal acts proposed by the authors of the «Legal Research» and ensure their approval, as well as provide scientific justification and initiate the development of appropriate federal RTDs in the interests of the city of Moscow.

We also believe that the direction of public administration in the field of UUS development should be adequately reflected in the draft strategy for the development of the construction industry and housing and communal services of the Russian Federation until 2035, which is being developed by the Ministry of Construction, since this area, of course, has a strategic character, responding to modern urban trends.

\section{References}

1. Resolution adopted by the General Assembly 25 September, 70th session. Paragraphs 15 and 116 of the agenda. 70/1. Transforming Our World: the 2030 Agenda for sustainable development (2015)

2. Monitoring and analysing regulations in the area of integrated urban development of underground space, including engineering and land planning for urban development of underground space, preparation of proposals for the prospective composition and structure of a set of regulatory technical documents in the area under consideration», https://synapsenet.ru/zakupki/fz223/31705107614--moskva-vipolnenie-rabot-pomonitoringu-i-analizu-normativnih.

3. Urban Planning Code of the Russian Federation № 190-FZ (2004)

4. Russian Federation Federal law № 384-FZ of 28.06.2014 «Technical regulations on the safety of buildings and structures»

5. Guidelines for drawing up schemes for integrated use of underground space in large and major cities, https://files.stroyinf.ru/Data2/1/4294851/4294851114.pdf

6. Guide to the complex development of underground space in large cities, https://files.stroyinf.ru/Data1/45/45107/

7. Buildings, structures and complexes are underground. Urban design rules, https://www.faufcc.ru/technical-regulation-in-constuction/formulary-list/?s=473
8. Russian
Federation
Standard
GOST $\quad R$
1.2-2016, http://www.consultant.ru/cons/cgi/online.cgi?req=doc\&base=OTN\&n=11617\#099664 78158386016

9. Law of the Russian Federation of 21.02.1992 N 2395-1 «On subsoil» 
10. «Civil code of the Russian Federation» (part one) № 51-FZ (1994)

11. H. Li, A. Parriaux et al., The Joint HKIE-HKIP Conference on Planning and Development of Underground Space, 53-60 (2011)

12. Set of Russian Federation Regulations SR 42

13. V. Belyaev, Econom. of constr. and environment. management 2(67), 27-34 (2018)

14. «Land Code of the Russian Federation» № 136-FZ (2001)

15. Resolution Of the government of the Russian Federation of 16.02.2008 № 87 «On the composition of sections of project documentation and requirements for their content» 